\title{
Contracampo
}

\section{A PLATAFORMA @BRNASRUAS E A FORMAÇÃO DE MEMÓRIA COLETIVA SOBRE OS PROTESTOS DE JUNHO DE 2013 NO BRASIL}

\section{THE @BRNASRUAS PLATFORM AND THE FORMATION OF COLLECTIVE MEMORY ABOUT JUNE PROTESTS IN BRAZIL}

Niterói (RJ), v. 35, n. 3

dez/2016-mar/2017

A Revista Contracampo é uma revista eletrônica do Programa de Pós-Graduação em Comunicação da Universidade Federal Fluminense e tem como objetivo contribuir para a reflexão crítica em torno do campo midiático, atuando como espaço de circulação da pesquisa e do pensamento acadêmico.

\section{MARIA CLARA AQQUINO BITTENCOURT}

Professora e pesquisadora do Programa de Pós-Graduação em Ciências da Comunicação da Universidade do Vale do Rio dos Sinos. Pós-Doutora em Ciências da Comunicação pelo mesmo programa. Doutora e mestre em Comunicação e Informação pelo Programa de Pós-Graduação em Comunicação e Informação da Universidade Federal do Rio Grande do Sul. Graduada em Comunicação Social, habilitação Jornalismo, pela Universidade Católica de Pelotas. Brasil.

\section{PPG|COM}

AO CITAR ESTE ARTIGO, UTILIZE A SEGUINTE REFERÊNCIA:

BITTENCOURT, Maria Clara Aquino. A Plataforma @BRnasruas e a Formação de Memória Coletiva sobre os Protestos de Junho de 2013 no Brasil. Contracampo, Niterói, v.35, n. 03, dez. 2016/ mar. 2017. 


\section{Resumo}

Este artigo observa a plataforma @BRnasRuas, agregadora de conteúdo sobre os protestos que aconteceram em junho no Brasil. O objetivo é identificar como a plataforma registra e recupera conteúdos espalhados na rede através de hashtags e como tais processos estão relacionados com a formação de memória. A observação da plataforma e uma entrevista com um de seus criadores auxiliou no entendimento sobre o funcionamento do site e na avaliação dos mecanismos de filtragem e colaboração para entender o impacto da produção colaborativa na formação e na manutenção de uma memória coletiva sobre os protestos no país.

\section{Palavras-chave}

memória coletiva; @BRnasruas; hashtags

\section{Abstract}

This paper notes the platform @BRnasRuas, which is an aggregator of content about the protests that happened in June in Brazil. The objective is to identify how the platform records and retrieves contents scattered on the network through hashtags and how these processes are related to memory formation. The observation of the platform and an interview with one of its creators has aided the understanding of the functioning of the site and evaluation of filtering and collaboration to understand the impact of collaborative production in formation and maintenance of a collective memory about the protests in the country. The case study in question contributes to the understanding of changes in the field of journalism from the use of digital communication technologies.

\section{Keywords}

collective hashtags memory; @BRnasruas; 


\section{Introdução}

A incorporação de ferramentas de comunicação no cotidiano de movimentos sociais, que ocorre há muito antes da criação e desenvolvimento da Internet e da web, vê hoje na conexão sem fio e no uso de dispositivos móveis a ampliação de oportunidades midiáticas antes limitadas. Gohn (2010) relata que essa apropriação fortalece possibilidades de articulação e estratégias de visibilidade aos movimentos, reconfigurando formas de organização e ação. Para Castells (2012), esse suporte técnico ampara a constituição de uma forma de manifestação mais horizontal e menos centralizada, através da qual, fluxos alternativos de informação recebem tanta atenção quanto os da mídia tradicional. De fato, a ocorrência de levantes populares nos últimos anos, como o movimento de Seattle (1999) e as manifestações da Primavera Árabe (2011), torna ainda mais latente a reflexão sobre as práticas comunicacionais orientadas pelo engajamento coletivo na construção e no uso de ferramentas digitais de comunicação para reportar os fatos e divulgar causas de movimentos diversos.

$O$ aproveitamento das possibilidades digitais na narrativa das ruas revela um fluxo de informação paralelo ao estabelecido pela mídia de massa. Retomando a teoria dos campos de Bourdieu (1983), é preciso reconsiderar a composição do campo midiático como representante legítimo de outros campos da sociedade. Este campo já não é mais formado unicamente pela mídia de massa. A apropriação da internet, web e demais ferramentas digitais de comunicação por movimentos, ativistas e cidadãos reflete a inserção de novos atores no campo midiático, os quais interferem no fluxo informacional. A produção e a circulação de conteúdo através das redes retira da mídia de massa o monopólio da narrativa sobre os protestos (MALINI E ANTOUN, 2013) e assim amplia espaços pelos quais a informação fica registrada e pode ser recuperada.

Este artigo observa a plataforma @BRnasRuas ${ }^{1}$, agregadora 
de conteúdos sobre os protestos no Brasil e publicados por contas no Facebook, Twitter, blogs e sites independentes. O mapeamento da informação é feito através de hashtags e filtros que buscam os conteúdos. Entende-se que esse tipo de plataforma faz parte de um fluxo informacional sobre os protestos paralelo ao fluxo da mídia de massa. Assim, o objetivo é identificar como se dá o registro e a recuperação de conteúdos através de hashtags de conteúdos espalhados pela rede e como tais processos estão relacionados com a formação de memória. A observação do funcionamento da plataforma e a interpretação das respostas a uma entrevista com um de seus criadores auxiliaram no entendimento sobre o funcionamento do site e na avaliação dos mecanismos de filtragem e colaboração para entender o impacto da produção colaborativa na formação e na manutenção de uma memória coletiva sobre os protestos no país. O estudo do caso em questão contribui para uma pesquisa que investiga transformações no campo do jornalismo digital a partir de apropriações de tecnologias digitais de comunicação por grupos independentes que visam produzir conteúdo acerca de movimentos sociais e mobilizações em rede.

\section{Recuperação de informação no contexto digital e memória coletiva}

Nos anos 90, Lévy (1996) dizia que a partir do hipertexto da web toda a leitura havia transformado-se em ato de escrita, em função das possibilidades de se criar e modificar links entre documentos. No entanto, a verdade é que o hipertexto do início da web limitava a atividade dos que não sabiam programar a navegação não linear pelas páginas. A disposição dos links e a inserção de conteúdo eram privilégios de poucos, ainda que logo a liberdade de emissão de conteúdo viesse a crescer de forma significativa a partir do desenvolvimento de ferramentas de fácil manuseio, como os blogs, por exemplo. Com o aumento da quantidade de informação na rede ampliou-se ainda mais a discussão em torno da recuperação dos dados e da constituição de 
memória em torno dos acontecimentos.

No campo do jornalismo, Christofoletti e Laux (2008) lembram como a disseminação dos blogs desencadeou transformações em processos de apuração e difusão de informações, ao mesmo tempo em que provocou novas formas de relacionamento entre produtores e consumidores de informação. Os autores apontam diferentes usos dos blogs por parte de veículos jornalísticos, mostrando a pouca influência das páginas nas rotinas da imprensa. Mas a verdade é que os blogs ganharam a web antes de conquistarem o jornalismo. Recuero (2003) lembra a identificação inicial dos blogs como "tendência de diarismo na internet", para só posteriormente representar uma quebra de paradigmas no jornalismo. Ela considera que a Guerra do Iraque tornou clara a influência dos blogs no jornalismo com a proliferação dos warblogs - blogs que narravam os fatos da guerra e eram escritos tanto por pessoas sem formação jornalística quanto por jornalistas da imprensa oficial. ${ }^{2}$ Com a legitimação dos blogs como ferramenta jornalística nascem novas oportunidades de mídia para um fluxo informacional paralelo aos meios de massa.

No início dos anos 2000, Dreyfus (2001) apontava a geração dos links por qualquer indivíduo, conectando um documento a outro, como uma dificuldade de se encontrar informação online. Com a popularização da web, apropriações diversas surgiram para facilitar a recuperação de conteúdo. A colaboração já fazia parte de muitas dessas ferramentas ${ }^{3}$ e a folksonomia ${ }^{4}$ foi uma dessas apropriações que acabou incorporada pelos blogs, jornalísticos ou não, e também por sites e portais noticiosos. As tags (etiquetas) ao final dos posts e textos jornalísticos possibilitaram o mapeamento hipertextual de temas pela rede, facilitando a busca e a recuperação de conteúdos sobre qualquer assunto. Vander Wall (2006), criador do termo folksonomia, explica que "o valor desse etiquetamento externo deriva das pessoas usando

\footnotetext{
2 Recuero (2003) diz que na época foi criada a Warblogs.cc, plataforma agregadora de blogs de guerra. 3 A rede de fotografias Flickr (http://flickr.com) foi um dos primeiros sites a utilizar as tags para catalogar as imagens.

4 Termo utilizado para definir a prática de organização de arquivos através do uso de tags (etiquetas).
} 
seu próprio vocabulário e adicionando significado explícito, o que pode vir de um entendimento inferido daquela informação ou objeto" ${ }^{15}{ }^{6}$

No caso das redes sociais, o Twitter é o exemplo mais forte do uso das hashtags de forma colaborativa na organização e recuperação dos tweets publicados. Para a comunicação de movimentos sociais e coletivos no âmbito de mobilizações sociais em rede, a prática tem sido fundamental na organização de atos e protestos e para o registro e a recuperação dos conteúdos publicados sobre os acontecimentos. 0 mapeamento das hashtags no Twitter tem servido para a investigação científica sobre os movimentos ao redor do mundo, como se pode observar nos estudos de Toret (2012), Recuero (2014) e Bastos, Recuero e Zago (2014). Assim, a possibilidade de qualquer indivíduo etiquetar conteúdo online altera os padrões hipertextuais da rede, já que a colaboração em torno da criação das hashtags permite a organização semântica das informações, ampliando caminhos de busca por informação online. Diante da constituição de um fluxo informacional paralelo ao estabelecido pela mídia de massa, as hashtags são fundamentais para o mapeamento desse conteúdo. Recuperar informações espalhadas pela rede sob inúmeros perfis em redes sociais, sites e blogs independentes é tarefa facilitada através das hashtags e de ferramentas que reúnem conteúdo a partir do mapeamento dessa prática coletiva.

\section{As narrativas dos protestos nas redes}

Observar as formas pelas quais atores diversos vêm construindo e espalhando histórias e informações através das redes é um caminho para identificar como o jornalismo pode e precisa ser reconfigurado diante da pluralidade de usos e apropriações comunicacionais. Nunes (2014), entre outros autores, trabalha com a ideia de sistema-rede para pensar os protestos que vêm ocorrendo não só no Brasil, mas em

5 Aquino (2007) aborda a folksonomia como um novo tipo de hipertexto na segunda fase da web. Disponível em: http://goo.gl/WTfhp1

6 "The value in this external tagging is derived from people using their own vocabulary and adding explicit meaning, which may come from inferred understanding of the information/object" 
outros países.

O sistema-rede é um sistema com diversas camadas, cada uma das quais é uma rede: a rede de pessoas na rua, de perfis do Facebook, de contas do Twitter, de espaços físicos em que as pessoas se encontram. As camadas não são redutíveis uma a outra. Nem todo mundo está em todas, e a rede no Twitter é diferente daquela do Facebook, que é diferente daquela do mundo físico. Os laços são outros, os nós são outros. Mas elas pertencem todas ao mesmo sistema, ou seja, interagem todo o tempo.

Essa estrutura em camadas também é abordada por Toret (2012) em sua análise sobre o movimento espanhol \#15M. Ele explica que a circulação de informação pela internet através de redes sociais, coletivos de notícias, blogs e até pelos meios estrangeiros ao mesmo tempo em que rompeu o monopólio de agendamento feito pela mídia de massa, obrigou a mesma a noticiar o que acontecia nas ruas. 0 que aconteceu foi a geração de um sistema rede composto por formas organizativas distribuídas pelas camadas física e digital, responsáveis por ampliar e dar sentido ao sistema através de uma narrativa coletiva transmidiática.

É fato que, não apenas na Espanha, as informações sobre os protestos partem de múltiplas origens: mídia de massa, mídia independente, cidadãos e movimentos têm acesso a dispositivos e espaços de publicação de conteúdo. Esse ambiente é cada vez mais mediatizado pela comunicação de massa e pela autocomunicação de massa, explica Nunes (2014). O filósofo lembra que na época das Diretas, com o país ainda sob o controle da ditadura e com a mídia bloqueada, era necessário o aporte de organizações estruturadas nacionalmente e lideranças que se deslocassem pelo país. Hoje, ele chama a atenção sobre como se fortalece, cada vez mais, um fluxo contínuo de informação que trafega por diferentes meios, e destaca oportunidades de participação desse fluxo através da emissão de opiniões, propostas e sentimentos. Malini e Antoun (2013, p. 157) se debruçam sobre esses processos de "narração coletiva dos acontecimentos públicos", e os entendem como o laboratório das disputas entre a velha e a nova mídia, entre o governo e as corporações e os movimentos, ativistas 
e cidadãos. Disso, entendem que devem resultar "novas narrativas multitudinárias", que vão passar de um "modelo informacional baseado na "acumulação quantitativa prioritária de produtos, para o modelo comunicacional das multimídias, que privilegia a coordenação da ação coletiva dos movimentos."

A adoção de ferramentas de comunicação digital tem sido central na condução de narrativas ao vivo sobre atos e manifestações de rua. Zago (2011) comenta que o uso dessas ferramentas por indivíduos sem formação jornalística se traduz tanto como fator de colaboração para a produção de notícias em veículos tradicionais, como para publicação em espaços autônomos. O aproveitamento da velocidade de publicação no Twitter aparece nas coberturas dos mais diversos eventos, e não vem sendo diferente nos protestos ao redor do mundo como, por exemplo, nos casos do Occupy Wall Street, nos Estados Unidos, e Indignados, na Espanha, em 2010 e Primavera Árabe, no Oriente Médio, em 2011.

A apropriação dessas mídias sociais vai além do Twitter e do Facebook, explorando outras plataformas para potencializar a comunicação no âmbito dos protestos e mobilizações de rua, mas são as contas nas redes sociais e os sites e blogs que concentram as informações sobre o que se passa nas ruas. Lotan et al. (2011) analisaram o uso do Twitter nas revoluções no Egito e na Tunísia e verificaram que ainda que mais jornalistas do que blogueiros tenham atuado como fontes de informação, blogueiros e ativistas obtiveram mais alcance na divulgação de informações sobre os acontecimentos nas ruas. Para os autores, os meios de massa adotam o Twitter para ampliar o público e o envolvimento com o mesmo, o que acaba por alterar a forma como dependem de outras fontes e as republicam.

Malini (2013) enxerga um movimento feito por alguns veículos de imprensa para capturar as narrativas das redes sociais para a narrativa jornalística e a partir dessa percepção aborda a relação entre autoridade e centralidade quando a imprensa também atua nas redes sociais. Em 
julho de 2013 a Folha de São Paulo publicou matéria7 afirmando que o conteúdo produzido sobre os protestos de junho por jornais, portais e canais de televisão brasileiros havia dominado o compartilhamento nas redes sociais. Malini (2013) explica que o jornalismo da imprensa formada por grandes e até pequenas empresas alcança altos níveis de compartilhamento pelo fato dessas empresas terem acesso rápido ao poder constituído e a determinados setores da sociedade civil, além de concentrarem recursos financeiros que possibilitam a proximidade e o controle das fontes. A distribuição de informação pela imprensa nas redes sociais gera o compartilhamento, ocasionando a autoridade de perfis noticiosos. No entanto, perfis oficiais de mobilização também podem ter conteúdos compartilhados em grande escala, pois detêm informações exclusivas sobre fatos e estratégias. O autor alerta para o fato de que autoridade não é a mesma coisa que centralidade, que os ativistas detêm. Enquanto perfis da imprensa concentram o uso das redes sociais sob um modelo de distribuição de conteúdos e informações para milhares de seguidores, a densidade das relações é maior e os níveis de interação são mais intensos entre os ativistas, que dialogam, compartilham e republicam uns aos outros através das redes sociais. Assim, Malini (2013) diz que "a centralidade mensura a capacidade de um "nó" (um perfil nas redes sociais) de ser capaz de atrair conexões, distribuir conexões, ser ponte para outras pessoas, articular mundos". Conforme o autor, não adianta um perfil de um veículo de imprensa possuir autoridade e ao mesmo tempo estar isolado dos indivíduos que interagem intensamente em torno de outros perfis.

Enquanto a mídia de massa parece ainda seguir um modelo de comunicação baseado na unilateralidade da produção e na distribuição de conteúdo, a comunicação sobre os acontecimentos nas ruas por movimentos, coletivos e cidadãos é baseada na produção e distribuição coletivas. Enquanto um veículo jornalístico concentra matérias e reportagens em arquivos recuperáveis através de links e hastags

7 Disponível em: $\underline{\text { http://goo.gl/12edx0 }}$ 
internas aos sites e portais, a produção colaborativa dos movimentos se espalha pela rede em diversos espaços online, representados por perfis em redes sociais, hoje principalmente pelo Twitter e Facebook. Toret (2012) defenda o uso do Twitter no contexto das mobilizações - por ser mais aberto que o Facebook -, mas é importante destacar aqui que a ferramenta apresenta dificuldades na recuperação de conteúdo mais antigo. No Twitter, sem contar com outros mecanismos de recuperação de tweets $^{8}$, não é possível recuperar todos os tweets de uma conta. Em ferramentas como Facebook, as publicações não desaparecem com o tempo, podendo ser recuperadas; ainda que a busca deste site de rede social não ofereça mecanismos para pesquisa avançada, fazendo que a procura seja mais demorada, em alguns casos.

Dessa forma, toda a atividade colaborativa em torno de perfis, sites e blogs que publicam sobre protestos e mobilizações de rua, independente da produção de conteúdo distribuída pela mídia de massa, interfere na maneira como as informações são armazenadas e recuperadas posteriormente. Para entender como esse fluxo de informações paralelo à mídia de massa vem atuando na mediação da memória coletiva sobre os protestos de junho de 2013 no Brasil, o próximo item recupera algumas considerações sobre memória.

\section{Memória coletiva}

Construir uma lembrança é vasculhar uma rede de associações na memória, e o mesmo se faz online, através do hipertexto. Para Halbwachs (2004), para pensar a evocação de lembranças é preciso considerar os quadros sociais que servem de referência para a memória. As lembranças dependem desses quadros de referência no qual indivíduos e grupos evoluem. Ele lembra que os seres humanos são sociais, pois sempre contam com a participação de memórias alheias. Essa formação de impressões com base não só na própria memória confere maior confiança na exatidão daquilo que buscam.

8 Mecanismos como o Topsy (http://topsy.com/) auxiliam na recuperação de tweets. 
Gondar (2006) entende a memória como algo construído através de relações sociais, algo que vai além da verdade pura e simples de um ocorrido. Na mesma linha, Sepúlveda (2003, p. 25) afirma que "a memória está presente em tudo e em todos", refletindo a ideia de conexão entre indivíduos e meios que influenciam na construção da memória. A autora apoia-se em Halbwachs para argumentar que a memória é sempre coletiva.

Tais argumentações não abordam o contexto online e a constituição da memória coletiva a partir de usos e apropriações de dispositivos digitais, mas podem ser apropriadas para uma reflexão nesse sentido. A formação da memória dos protestos de junho de 2013, além dos conteúdos veiculados pela mídia tradicional, pode ser amparada na atividade de perfis de redes sociais, sites e blogs independentes que relatam os acontecimentos e mapeiam as informações através de práticas coletivas de produção e circulação de conteúdos. Casalegno (2006, p. 21) entende que a memória coletiva ocorre "quando toda a coletividade pode acessá-la e nutri-la, porque são os indivíduos que participam de sua criação, e não as instituições oficiais". Pautados pela construção de meios e formatos mais democráticos que os instituídos pela mídia de massa, movimentos e coletivos sociais apropriam-se de ferramentas que permitem, além do acesso público, a inserção de conteúdo de forma colaborativa. ${ }^{9}$

Padrões de rede vêm guiando a narrativa independente sobre os acontecimentos nas ruas. Gutierrez (2013) aponta memes, estética, processos e protocolos compartilhados na configuração dos movimentos em rede. O mesmo se aplica aos que trabalham conteúdos sobre os protestos com base na lógica das redes e na exploração de formatos de visualização em conjunto com táticas de ocupação do espaço público como forma de cobertura e ativismo. A ocupação do espaço público transcende as ruas através da conexão e assim identidades coletivas reverberam os conteúdos colaborativos sobre os acontecimentos pelas

9 Em resposta à entrevista, Gutierrez, um dos criadores do @BRnasruas, afirma que o trabalho desenvolvido na plataforma busca se diferenciar do modelo de comunicação da mídia de massa. 
redes, colocando em discussão além das causas, o poder da mídia de massa sobre a narração dos acontecimentos. Nesse cenário, a formação da memória sobre os protestos, que já não dependia unicamente da mídia de massa antes do surgimento da internet e de tecnologias digitais de comunicação, é potencializada em diferentes espaços online. A produção de conteúdo descolada da imprensa tradicional e impulsionada pela circulação nas redes vem cada vez mais fortalecendo seu papel no imaginário coletivo sobre os protestos, contribuindo para o estabelecimento de um fluxo informacional paralelo e guiado pela lógica das redes.

Focado nas tecnologias digitais e na relação entre memória, comunidade e redes, Rösnay (2006) acredita na configuração de memória implícita e memória explícita. A explícita é composta pelas informações armazenadas em bases de dados, podendo ser recuperada por mecanismos de busca. A implícita é autoconstruída como um link na $w e b$, que quando criado constitui-se em uma via de acesso, um link implícito de memória. Pelo fato de permitirem a intercomunicabilidade na web, o autor considera que os links, aliados a interação e intercriação, favorecem a memória coletiva na rede. Logo, é através da liberdade de intervenção na construção do hipertexto, das conexões que o formam e do contínuo enriquecimento e gerenciamento dessas conexões que os indivíduos constroem e acessam uma memória coletiva e dinâmica, que está sempre em movimento e aperfeiçoamento a partir da colaboração.

O próximo item apresenta a plataforma @BRnasruas.

\section{5. @BRnasruas}

A ideia de criar o @BRnasruas nasceu no final de junho de 2013, em uma lista de e-mails que reunia pessoas e coletivos atuantes nos protestos que aconteciam naquela época no Brasil. O site foi lançado em fevereiro de 2014. Bernardo Gutierrez, um dos criadores da plataforma, em entrevista para este estudo, explica que inicialmente a lista agregou assembleias, movimentos de ocupação e pessoas 


\section{Contracampo}

especialmente ativas nos protestos. Em seguida surgiram os perfis no Facebook e Twitter. Ele diz que o objetivo principal não era a quantidade de informações nos perfis, mas o estabelecimento de relações através do compartilhamento e da conexão entre pessoas e informações. Cerca de 300 pessoas formaram, através dos diálogos sobre os protestos, segundo Gutierrez, um "ecossistema" que acabou gerando o desenvolvimento da plataforma. Gutierrez descreve o site como "um semi agregador ao serviço do bem comum". O principal trabalho é de curadoria, de escolha de fontes - sempre independentes - e da inserção de filtros que eliminam ruído, como spam e outras mensagens. O funcionamento se dá pelo recolhimento de contas no Twitter, através de uma lista própria da conta do @BRnasruas, fanpages no Facebook e RSS de blogs. Algumas hashtags também são escolhidas como forma de garimpar a informação. Além da página inicial, outras seis seções reúnem conteúdo sobre os protestos: \#ACidadeÉNossa; \#OcupaCopa; ProtestosBR; Vandalismo Policial; Passe Livre e \#OcupeAMídia.

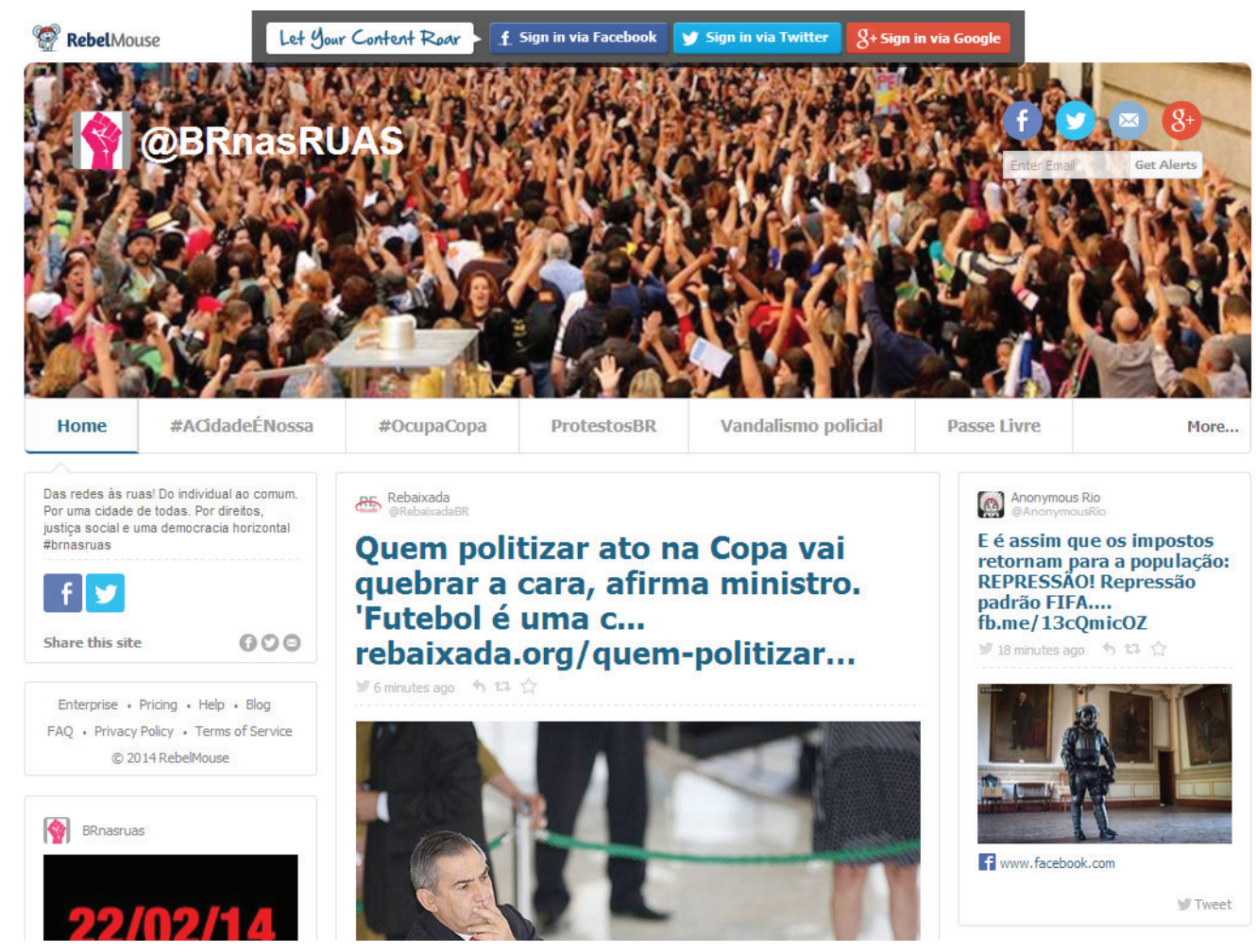

Plataforma @BRnasruas - http://brnasruas.com 
Por ser uma plataforma semi automatizada, a publicação é feita a partir da seleção das contas de redes sociais e blogs. Este filtro é feito pelos administradores da conta do @BRnasruas no Facebook e alguns editores, de forma que não há como especificar quantas pessoas contribuem com o conteúdo disponibilizado na plataforma cada conta selecionada pode ser editada por uma ou mais pessoas. Após a definição de uma hashtag, os conteúdos entram numa fila de rascunhos e precisam ser aprovados por algum dos editores. Se um conteúdo aparece no site e não é "considerado apropriado", nas palavras de Gutierrez, é removido. Ele explica que a filtragem é semi automática, pois precisa ser complementada pela curadoria humana: "@BRnasRuas poderia ser definido como jornalismo ciborg, pessoas e máquinas, algoritmos e sensibilidade humana". Logo, o conteúdo do @ BRnasruas é produto de contas em redes sociais e blogs previamente escolhidos para que suas publicações apareçam no site, através de compilação na lista 'Contas Coletivas'10 no Twitter, e de contas no Facebook. Há conteúdo próprio, inserido pelos editores, mas não existe um mecanismo ou seção através do qual um indivíduo possa enviar conteúdo para que seja publicado no site.

A plataforma de base do @BRnasruas é a RebelMouse. ${ }^{11}$ Gutierrez explica que por ser muito complexa, algumas funções e o código vêm sendo modificados. As hashtags são importantes para a seleção dos conteúdos, mas ele destaca que a matriz do @BRnasruas é a curadoria coletiva ao longo dos meses posteriores aos protestos de junho.

Conteúdos sem link de acesso são deixados de fora, pela impossibilidade de se filtrar o volume de informações, mas não há preferência por formato (textos, fotos, vídeos, áudios ou links). O ideal é que o conteúdo seja independente. Conteúdo da mídia de massa só aparece quando alguma das contas selecionadas compartilha, mas Gutierrez diz que é raro acontecer, "já que a grande mídia brasileira

10 https://twitter.com/BRnasRuas/contascoletivas/

11 https://www.rebelmouse.com/ Plataforma que potencializa a publicação de conteúdo independente valorizando a instantaneidade das publicações. 
é muito ruim e manipula muito os protestos". Quando questionado sobre o modelo do @BRnasruas, ele diz que o site busca se diferenciar totalmente da mídia de massa em seu modelo de comunicação, atuando como "um filtro na era da abundância" e enfatiza o caráter não comercial do site, pontuando que nunca aceitará publicidade.

O @BRnasruas promove a circulação dos conteúdos agregados via replicação no Twitter e Facebook. Gutierrez aponta que como cada post gera uma url distinta, o SEO ${ }^{12}$ do Google auxilia nessa replicação. No entanto, a plataforma ainda não oferece uma forma definida para a recuperação do conteúdo agregado. Junto com cada conteúdo ficam visíveis botões de compartilhamento no Twitter e no Facebook, além da opção de se favoritar o conteúdo para uma leitura posterior. Qualquer indivíduo pode se cadastrar na plataforma e armazenar o conteúdo para leitura. Também é possível assinar a newsletter do @BRnasruas para receber uma compilação de conteúdos.

\section{Metodologia e análise}

Como metodologia optou-se pelas técnicas de observação e entrevista, com base em Fragoso, Recuero e Amaral (2011) e Duarte e Barros (2008). A observação buscou identificar a estrutura básica de funcionamento da plataforma para identificar o papel das hashtags na constituição da memória. Em função da ausência de informações sobre os critérios de filtragem de conteúdos, considerou-se relevante realizar uma entrevista, que foi feita por e-mail, ${ }^{13}$ com Bernardo Gutierrez, um dos criadores do site.

Inicialmente, é preciso considerar que a criação de uma plataforma agregadora de conteúdo sobre os protestos só é possível a partir das possibilidades de articulação e de estratégias de visibilidade trazidas pela adoção de tecnologias de comunicação no contexto dos movimentos sociais, como aponta Gohn (2010). Sua construção e

\footnotetext{
12 SEO - Search Engine Optimization - processo que afeta a visibilidade de um site dentro de um buscador.

13 As perguntas podem ser visualizadas em: http://goo.gl/kcZHFD
} 
manutenção fazem parte do fluxo alternativo de informação (CASTELLS, 2012). Primeiro pelo fato de agregar apenas conteúdo independente, e depois por práticas como a reunião de contas de identidades coletivas, como menciona Gutierrez ao se referir às contas selecionadas, assim potencialmente retirando o monopólio de narração da mídia de massa (MALINI E ANTOUN, 2013), ao auxiliar na expansão da visibilidade dos conteúdos espalhados pela rede. Porém, não há como ignorar o fato de que a plataforma, por ser agregadora, tem potencial colaborativo limitado, já que existe uma seleção prévia do conteúdo que será agregado.

Ao explicar a motivação do @BRnasruas, Gutierrez menciona a formação de "um novo sujeito político-social", que surgiu nas jornadas de junho. Esse sujeito configura-se nas identidades coletivas em contas de Twitter e Facebook e blogs de movimentos e coletivos independentes que relatam os protestos. Ao afirmar que o objetivo não era a quantidade de informações publicadas nos perfis, mas o estabelecimento de relações através do compartilhamento e da conexão entre pessoas e informações, Gutierrez explicita novas formas de relacionamento entre produtores e consumidores de informação, como quando Christofoletti e Laux (2008) relatam sobre da popularização dos blogs. A seleção e a filtragem de contas tem como base uma rede de compartilhamento e diálogo que nasce em meados de junho e embasa a constituição da plataforma a partir de conversações que não aparecem no site, mas pesam no momento da escolha de quais contas e blogs terão o conteúdo agregado no site. Quando Recuero (2003) menciona a plataforma Warblogs.cc a partir da necessidade de reunir o conteúdo de blogs sobre a Guerra no Iraque, percebe-se um movimento semelhante no @BRnasruas, mas ampliado na medida em que a agregação é feita não apenas de posts de blogs independentes, mas de diversas contas em sites de rede social que muitas vezes geram um volume grande de informação, dependendo da hashtag utilizada ${ }^{14}$.

14 Recuero (2014) analisa as hashtags \#calaabocadilma e \#tamojuntodilma, oferecendo possibilidades de mineração análise de grandes quantidades de informações reunidas sob as hashtags. 
A quantidade de conteúdo é também um dos fatores que dificulta o trabalho do @BRnasruas. Como relata Gutierrez, o recolhimento de informações ainda é limitado a conteúdos com links, o que, por um lado facilita o trabalho, mas por outro exclui muita informação espalhada pela rede. Se no início dos anos 2000 Dreyfus (2001) considerava a quantidade de links uma dificuldade para encontrar e recuperar conteúdo online, no caso do @BRnasruas a inexistência de links impede o seu funcionamento. Aqui, o papel da folksonomia é fundamental para o funcionamento do site. As hashtags funcionam como agregadoras de conteúdo e orientam a formação da memória coletiva sobre os protestos, pois partem de fontes diversas. A filtragem feita através das hashtags é o aspecto que mais agrega coletividade ao conteúdo que aparece no @BRnasruas, pois além de serem utilizadas pelas contas coletivas selecionadas previamente, também são por perfis individuais, que podem assim alcançar visibilidade junto aos editores da plataforma. É fato, no entanto, que a escolha prévia das hashtags também limita a informação que circula na plataforma.

A escolha das hashtags é pautada pela popularidade das mesmas, o que indica que a memória coletiva em torno dos protestos, ao mesmo tempo em que é acessada por uma grande quantidade de pessoas, é nutrida por diversos perfis (CASALEGNO, 2006). Aqui a importância das relações sociais na construção de narrativa baseada em colaboração e engajamento coletivo impulsiona a plataforma que, ainda que não seja alimentada por todos, limitada ao poder dos editores, tem o conteúdo produzido por autores diversos. Os quadros sociais que Halbwachs (2004) menciona como referência para a reconstrução da memória são ativados através das hashtags, que reúnem diálogos e compartilhamentos independente da veiculação de informação praticada pela mídia de massa. A coletividade, ao utilizar as hashtags para marcar informações, dinamiza uma rede hipertextual semântica sobre os protestos. As conexões as quais Sepúlveda (2003) confere a responsabilidade pela formação da memória coletiva são resultado das relações sociais estabelecidas em redes sociais e blogs. Os links e as 
hashtags são os elos, o hipertexto que costura essa memória e permite o acesso aos conteúdos espalhados online.

A força que o hipertexto, através de links e hashtags, confere ao @BRnasruas o status de ferramenta capaz de contribuir para a formação de uma memória coletiva sobre os protestos. Segundo a classificação de Rösnay (2006), a memória explícita da plataforma decorre da memória implícita de perfis que atuam como identidades coletivas, e também de indivíduos, que distribuem informações na rede, marcando conteúdos através de links e hashtags e que dessa forma auxiliam a formação de memória coletiva sobre os protestos. Toda a liberdade garantida através da geração de links e hashtags, bem como das conversações geradas em torno dessa rede hipertextual, são fatores que dinamizam constantemente a memória coletiva que reside na plataforma. Ainda persistem obstáculos referentes à recuperação dessa memória. Um sistema de busca avançada auxiliaria no resgate de conteúdos que já apareceram no site, mas não figuram mais nas seções, e até mesmo para os que ainda circulam pelas seções. Gutierrez afirma que há um esforço no sentido de melhorar esse processo. Pode ser que a colaboração guie esse mecanismo, já que a plataforma funciona baseada na hipertextualidade de links e tags gerados por uma quantidade indefinida de indivíduos e identidades coletivas.

O funcionamento do @BRnasruas também apresenta sobreposição de camadas física e digital que alimentam o site através de uma narrativa coletiva transmidiática, como aborda Toret (2012). A diversidade de conteúdos, ainda que previamente filtrada, fornece informações sob diferentes formatos, sobrepostos com diálogos e compartilhamentos que atestam caráter social ao processo de produção e circulação de informações e movimentam a memória coletiva sobre os protestos. Entende-se, diante desta descrição, que a plataforma @BRnasruas constitui uma ferramenta alternativa de consulta sobre os protestos, por quem quer que seja, jornalista ou não. 


\section{Considerações finais}

Buscou-se aqui abordar como a maneira pela qual a plataforma @BRnasruas contribui para a formação de uma memória coletiva sobre os protestos de junho de 2013 no Brasil. A ferramenta se apresenta como um espaço onde os conteúdos reunidos podem ser recuperados posteriormente, abrindo espaço para a configuração de um processo capaz de gerar memória coletiva em função de uma rede hipertextual movida por atores diversos, entre identidades coletivas e perfis individuais. Para o jornalismo, a ocorrência desse fluxo alternativo de informações acarreta mudanças na produção diária de notícias sobre os protestos. Além de servir como fonte de conteúdo, o @BRnasruas concorre, ou corre em paralelo, com o jornalismo da imprensa tradicional. A reunião de informações publicadas em contas de redes sociais e blogs independentes serve como pauta e modelo de comunicação, enquanto que a organização de conteúdo em sites e portais de notícias da mídia tradicional pode servir de exemplo e indício de soluções para deficiências de recuperação de conteúdo na plataforma. É preciso, no entanto, considerar as limitações do sistema em termos de filtragem e de recuperação das informações. A moderação poda oportunidades de participação tornando o sistema semi colaborativo; e a carência de mecanismos de busca interna prejudica o resgate de conteúdos já agregados.

Como já dito, padrões de rede vêm guiando a narrativa independente sobre os acontecimentos nas ruas do país. O espalhamento de informação por identidades coletivas interfere no fluxo midiático anteriormente controlado pela mídia de massa. A autoridade da narrativa é disputada pela mídia de massa, enquanto que a mídia independente, ao concentrar a centralidade das informações, demonstra por um modelo de comunicação diferente, mais democrático e transparente. A observação do @BRnasruas aponta traços desse esforço, ao mesmo tempo em que identifica ranços de um modelo distributivo moldado pelo controle. $O$ enfrentamento entre as mídias barra o desenvolvimento de 
um novo modelo, e por mais que alguns processos ainda dependam de amarras de moderação e filtro, o jornalismo ganha com a apropriação de ferramentas de comunicação digital orientadas pela colaboração e pelo engajamento.

\section{Referências}

BASTOS, M. T.; RECUERO, R.; ZAGO, G. Taking tweets to the streets. A spatial analysis of the Vinegar Protests in Brazil. In: First Monday, v.9,n.3, 2014. Disponível: http://goo.gl/xQnVVO

BOURDIEU, P. Questões de sociologia: algumas propriedades dos campos. Rio de Janeiro: Marco Zero, 1983.

CASALEGNO, F. Memória cotidiana: comunidades e comunicação da era das redes. Porto Alegre: Editora Sulina, 2006.

CASTELLS, M. Networks of outrage and hope: social movements in the internet age. Politik. Wiley, 2012.

CHRISTOFOLETTI, R. ; LAUX, AP. Confiabilidade, credibilidade e reputação: no jornalismo e na blogosfera. In: Intercom - Revista Brasileira de Ciências da Comunicação,v. 31, n. 1, 2008. Disponível: http://goo.gl/2z2Rof

DREYFUS, H.L. On the Internet. Londres: Routledge, 2001.

DUARTE, J.; BARROS, A. (orgs). Métodos e técnicas de pesquisa em comunicação. Editora Atlas: São Paulo, 2008.

FRAGOSO, S.; RECUERO, R.; AMARAL, A. Métodos de pesquisa para Internet. Porto Alegre: Sulina, 2011.

GOHN, MGM. Movimentos sociais e redes de mobilização civis no Brasil contemporâneo. Ed. Vozes: Petrópolis, 2010.

GONDAR, J. Quatro proposições sobre memória social. In: DODEBEI, Vera; GONDAR, J. O que é memória social? Rio de Janeiro: Contra Capa, 2006.

GUTIERREZ, B. Três anos de revoltas conectadas. Disponível: http:// goo.gl/Al10A6

HALBWACHS, M. A memória coletiva. São Paulo: Centauro Editora, 2004.

LÉVY, P. O que é o virtual? Rio de Janeiro: 34, 1996.

LOTAN, G. et al. The Revolutions Were Tweeted: Information Flows during the 2011 Tunisian and Egyptian Revolutions. International Journal of Communications 5, Feature 1375-1405. 2011. Disponível em: http://goo.gl/ Gxrc72

MALINI, F. Imprensa nas redes sociais: autoridade sem centralidade. In: 
Blog do Laboratório de Estudos sobre Imagem e Cibercultura. Disponível em: http://goo.gl/aBknEb

MALINI, F.; ANTOUN, H. @internet e \#rua: ciberativismo e mobilização nas redes sociais. Editora Sulina, Porto Alegre, 2013.

NUNES, R. As manifestações renovarão os mecanismos existentes ou criarão novos? Entrevista especial com Rodrigo Nunes; In: Instituto Humanitas Unisinos. Disponível em: http://goo.gl/RWSeoB

RECUERO, R. Warblogs: os blogs, a Guerra do Iraque e o Jornalismo Online. In: Verso e Reverso, São Leopoldo, n.37, p. 57-76, 2003.

RECUERO, R. Contribuições da Análise de Redes Sociais para o Estudo das Redes Sociais na Internet: $O$ caso da hashtag \#Tamojuntodilma e \#CalabocaDilma. [versão preprint ] (publicada com a autorização da revista) - Revista Fronteiras, v. 16, p. 1, 2014. Disponível em: http://goo.gl/Anq1BE

RÖSNAY, J. Memória em rede e intercriatividade. In: CASALEGNO, Federico. Memória cotidiana: comunidades e comunicação da era das redes. Porto Alegre: Editora Sulina, 2006.

SEPÚLVEDA, M.S. Memória coletiva e teoria social. São Paulo: Annablume, 2003.

TORET, J. Una mirada tecnopolítica sobre los primeros dias del \#15M. In: Comunicación y Sociedad Civil. 2012. http://goo.gl/iR5U6p

VANDER WAL, T. Folksonomy definition and Wikipedia. Disponível em: http://goo.gl/ZQNptx.

ZAGO, G. Considerações sobre a circulação de informações em sites de redes sociais. Fonte (Belo Horizonte), v. 8, p. 70-77, 2011. 